\title{
Geociências
}

\section{Caracterização mineralógica de azulejos de Salvador e Belém dos séculos XVI, XVII e XIX}

\author{
Thais A. B. Caminha Sanjad \\ Arquiteta, doutoranda do curso de Pós-Graduação em Geologia e \\ Geoquímica do Centro de Geociências da Universidade Federal do Pará. \\ E-mail:thais@ufpa.br \\ Rômulo Simões Angélica \\ Chefe do Laboratório de Raios Xe de Infravermelho, \\ Prof. Dr. do Centro de Geociências da Universidade Federal do Pará. \\ E-mail: angelica@ufpa.br \\ Mário Mendonça de Oliveira \\ Coordenador do Núcleo de Tecnologia da Preservação e da Restauração, Prof. Dr. do Programa \\ de Pós-Graduação da Faculdade de Arquitetura da Universidade Federal da Bahia. \\ E-mail:mmo@ufba.br \\ Walmeire Alves de Melo Costa \\ Geóloga, Técnica em Radiologia do Laboratório de Raios X do Centro de \\ Geociências da Universidade Federal do Pará. \\ E-mail:walmelo@ufpa.br
}

\section{Resumo}

O presente artigo trata da caracterização da composição mineralógica de azulejos antigos pertencentes aos séculos XVI, XVII e XIX, coletados em Salvador e Belém, visando à identificação da sua provável matéria-prima e a possível temperatura de queima. Quartzo foi identificado em todas as amostras. As demais fases cristalinas encontradas foram: mullita, cristobalita, calcita, anortita, hematita, gehlenita, diopsídio e wollastonita. Foi possível dividir as amostras em três grupos, em função da possível matéria-prima e temperatura de queima: grupo 1 - caulinita e quartzo, T entre $1200^{\circ}$ e $1728^{\circ} \mathrm{C}$; grupo 2 - quartzo, caulinita, calcita e/ou dolomita e óxido ou hidróxido de ferro, T entre $900^{\circ}$ e $1200^{\circ} \mathrm{C}$; grupo 3 - quartzo, argilominerais (provavelmente caulinita), calcita e/ou dolomita e hidróxido ou óxido de ferro, T entre $1200^{\circ}$ e $1565^{\circ} \mathrm{C}$.

Palavras-chave: Azulejo antigo, Belém, Salvador, mineralogia, temperatura de queima, matéria-prima.

\section{Abstract}

The present article is a study about the mineralogical composition of ancient tiles from centuries XVI, XVII and XIX, found in Belém and Salvador, in order to interpret the possible raw material and burning temperature. Quartz was identified in all samples. Other crystalline phases found are mullite, cristobalite, calcite, anorthite, hematite, gehlenite, diopside and wollastonite. Based on the probable raw material and probable burning temperature it was possible to organize the samples into three groups: group 1 - kaolinite and quartz, T between $1200^{\circ}$ and $1728^{\circ} \mathrm{C}$; group 2 - kaolinite, calcite and/or dolomite and iron oxide or hydroxide, T between $900^{\circ}$ e $1200^{\circ} \mathrm{C}$; group 3 - quartz, clay minerals (probably kaolinite), calcite and/or dolomite, iron oxide or hydroxide, and $T$ between $1200^{\circ}$ e $1565^{\circ} \mathrm{C}$.

Keywords: Ancient tile, Belém, Salvador, mineralogy, burning temperature, raw material. 


\section{Introdução}

Trabalhos como Oliveira (2001) e Malhoa (2001) ressaltam a importância do conhecimento interdisciplinar na conservação da herança cultural, evidenciando o novo rumo que integra as diversas ciências como essencial para a conservação dos revestimentos de azulejos.

O objetivo do presente estudo é o conhecimento da composição mineralógica de azulejos antigos, através da aplicação de um método instrumental aplicado à mineralogia, a difração de raios $\mathrm{X}$, de modo que os dados obtidos possam ainda caracterizar a possível matéria-prima utilizada para a sua fabricação e a provável temperatura de queima alcançada durante a sua cozedura.

São informações como essas, a respeito da matéria a ser restaurada, que podem e devem influenciar diretamente na escolha dos materiais e dos procedimentos a serem adotados durante uma intervenção restaurativa em azulejos.

\section{Materiais e métodos}

Foram analisadas vinte amostras, por difração de raios X, método do pó, da base cerâmica de azulejos produzidos nos séculos XVI, XVII e XIX, oriundos de Portugal, Espanha, Alemanha, Inglaterra e Holanda, sendo onze coletados na cidade de Salvador e nove em Belém. Não foi possível obter amostras setecentistas em função que a grande maioria de azulejos do século XVIII foi destinada a compor painéis historiados cuja falta de uma única unidade o prejudicaria ainda mais, pois cada peça tem uma pintura distinta de uma dada composição. É importante comentar que durante esse período não aconteceram grandes inovações tecnológicas no campo da cerâmica azulejar que comprometessem a presente análise por falta de informações. Além disso, a composição e técnica de fabricação usadas no século XVIII, tanto da base cerâmica, quanto da decoração, seguem os caminhos da utilizada no século XVII, sendo que aquilo que basicamente as diferencia são os motivos das pinturas dos azulejos.
O difratômetro pertence ao Laboratório de Raios X do Centro de Geociências da UFPA, é da marca Phillips, modelo PW 3710 básico, equipado com ânodo de cobre $\left(\lambda \mathrm{CuK} \alpha_{1}=1,54060\right)$, utiliza monocromador, gerador de tensão com $45 \mathrm{kV}$ e gerador de corrente com $40 \mathrm{~mA}$. O intervalo de varredura foi de $5^{\circ}$ a $65^{\circ}$, em função de aparecerem, nesse intervalo, os principais picos dos minerais, porém, nos casos em que houve necessidade, esse intervalo foi aumentado.

As composições mineralógicas foram obtidas a partir das interpretações dos difratogramas, utilizando-se o software APD - Automatic Powder Diffraction da Philips, que é um modelo matemático computadorizado utilizado no tratamento digital dos dados encontrados, e também o programa Minerva, que consiste em um banco de dados através de fichas com picos dos minerais e algumas outras características básicas, com base no ICDD - International Center for Diffraction Data.

Características físicas das amostras, como porosidade e densidade, foram também verificadas através dos métodos de absorção total em água e densidade pelo picnômetro de Hubbar $\left(\mathrm{g} / \mathrm{cm}^{3}\right)$, respectivamente, uma vez que tais propriedades estão intimamente relacionadas com as transformações mineralógicas que ocorreram na atmosfera dos fornos.

\section{Resultados}

Os resultados obtidos revelam uma composição mineralógica bastante diversificada e estão expostos na Tabela 1, a qual oferece, ainda, dados como a procedência das amostras e o século em que foram produzidas. O local onde foram coletadas pode ser identificado na nomeação das amostras, através da letra "B" para Belém e "S" para Salvador.

\section{Discussão}

Análises feitas a partir das fases cristalinas identificadas pela difração de raios $\mathrm{X}$ podem possibilitar a obtenção de dados referentes à provável matéria-prima utilizada e à possível temperatura de queima, o que Fabbri e Guidotti (1993) denominam de "termômetro mineralógico".

O quartzo, presente em todas as amostras, pode ter sido preservado da matériaprima, em função de a temperatura alcançada não ter sido superior a $870^{\circ} \mathrm{C}$, principalmente para o caso dos azulejos mais antigos (século XVI e XVII e determinadas fábricas do XIX), pois os fornos eram mais rudimentares. Outra possibilidade seria a formação do quartzo durante o resfriamento dos azulejos, no caso de a temperatura de queima ter ultrapassado a temperatura de transformação do quartzo em tridimita $\left(870^{\circ} \mathrm{C}\right)$ ou em cristobalita $\left(1470^{\circ} \mathrm{C}\right)$.

Provavelmente, a origem da cristobalita, presente em determinadas amostras do século XIX e uma do século XVII, esteja ligada à formação da mullita, através das reações que ocorrem com os argilominerais em um contínuo aumento de temperatura. Kirsch (1972) explica que a formação de mullita pode ocorrer a partir dos argilominerais caulinita, montmorilonita e illita. Na sucessão de reações que podem dar origem à formação de mullita com cristobalita, ocorre a formação intermediária de metacaulinita e espinélio artificial de Al e Si, colocado por Santos (1989) da seguinte maneira:

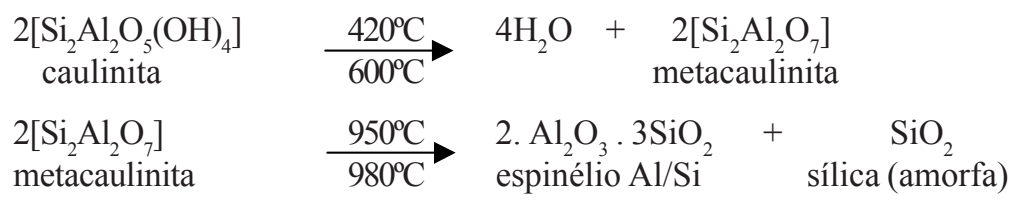


Thais A. B. Caminha Sanjad et al.

$$
\begin{aligned}
& 2 \mathrm{Al}_{2} \mathrm{O}_{3} \cdot 3 \mathrm{SiO}_{2} \\
& \text { espinélio } \mathrm{Al} / \mathrm{Si}
\end{aligned} \stackrel{1200^{\circ} \mathrm{C}}{1225^{\circ} \mathrm{C}} \underset{\begin{array}{c}
2 \\
\text { mulita }
\end{array}}{\left.2 \mathrm{Al}_{2} \mathrm{O}_{3} \cdot 2 \mathrm{SiO}_{2}\right)}+\begin{gathered}
\underset{\mathrm{SiO}}{2} \\
\text { cristobalita }
\end{gathered}
$$

Singer e Singer (1971) explicam que a mullita, quando formada a partir do caulim puro, a $1000^{\circ} \mathrm{C}$, aparece juntamente com sílica amorfa ou com tridimita; a partir de $1200^{\circ} \mathrm{C}$, ocorre formação da mullita com cristobalita e a $1770^{\circ} \mathrm{C}$ acontece a fusão do produto. A presença de minerais que possuem cálcio e/ou magnésio no biscoito (parte cerâmica) dos azulejos, como anortita $\left(\mathrm{CaAl}_{2} \mathrm{Si}_{2} \mathrm{O}_{8}\right)$, gehlenita $\left(\mathrm{Ca}_{2} \mathrm{Al}_{2} \mathrm{SiO}_{7}\right)$, wollastonita $\left(\mathrm{CaSiO}_{3}\right)$, diopsídio $\left(\mathrm{CaMgSi}_{2} \mathrm{O}_{6}\right)$, pode ser um forte indicativo de que a argila utilizada para fabricar as pastas cerâmicas continha carbonato. Provavelmente o material carbonático presente na matéria-prima era composto pelos minerais calcita $\left(\mathrm{CaCO}_{3}\right)$ e dolomita $\left(\mathrm{CaMg}\left(\mathrm{CO}_{3}\right)_{2}\right)$. A anortita pode provir de reações entre calcita e caulinita, como explica Kirsch (1972), através da expressão a seguir:

$$
\underset{\text { Calcita }}{\mathrm{CaCO}_{3}}+\underset{\text { Caulinita }}{2\left[\mathrm{Si}_{2} \mathrm{Al}_{2} \mathrm{O}_{5}(\mathrm{OH})_{4}\right]} \underset{\text { aquecimento }}{\rightarrow} \underset{\text { Anortita }}{\mathrm{CaAl}_{2} \mathrm{SiO}_{8}}+\mathrm{H}_{2} \mathrm{O}+\mathrm{CO}_{2}
$$

Não se pode afirmar se a calcita foi utilizada como fundente para diminuir o ponto de fusão do material ou se a mesma estava presente na argila, caracterizando-se como uma impureza carbonatada. A gehlenita $\left(\mathrm{Ca}_{2} \mathrm{Al}_{2} \mathrm{SiO}_{7}\right)$ é uma fase cristalina comum da cerâmica e resulta de uma argila com material carbonático e seu ponto de fusão ocorre a $1590^{\circ} \mathrm{C}$ (Vlack, 1973).

\begin{tabular}{|c|c|c|c|c|c|}
\hline Amostras & Século & Procedência & Resultado da Difração & $\begin{array}{l}\text { Porosidade } \\
\text { (\%) }\end{array}$ & $\begin{array}{c}\text { Densidade } \\
\left(\mathrm{g} / \mathrm{cm}^{3}\right)\end{array}$ \\
\hline B1-A & $\mathrm{XIX}$ & Alemanha & quartzo, mulita, cristobalita, calcita, anortita & 11,50 & 1,90 \\
\hline B1-B & $\mathrm{XIX}$ & Portugal & $\begin{array}{l}\text { quartzo, calcita, hematita (traços), gehlenita, } \\
\text { diopsídio, cristobalita (traços) }\end{array}$ & 24,42 & 1,60 \\
\hline$B 2-A$ & $\mathrm{XIX}$ & Alemanha (provável) & quartzo, mulita, cristobalita (traços) & 9,88 & 2,06 \\
\hline $\mathrm{B} 2-\mathrm{B}$ & $\mathrm{XIX}$ & Alemanha (provável) & quartzo, mulita, cristobalita (traços) & 10,46 & 1,87 \\
\hline B3 & $\mathrm{XIX}$ & Inglaterra (provável) & quartzo, mulita, cristobalita & 9,32 & 1,98 \\
\hline B4 & $\mathrm{XIX}$ & Inglaterra (provável) & quartzo, mulita, cristobalita, calcita & 12,04 & 1,94 \\
\hline B5 & $\mathrm{XIX}$ & Portugal & $\begin{array}{l}\text { quartzo, calcita, anortita, hematita, gehlenita, } \\
\text { wollastonita }\end{array}$ & 16,78 & 1,70 \\
\hline B6 & $\mathrm{XIX}$ & Portugal & $\begin{array}{l}\text { quartzo, calcita, anortita, hematita, gehlenita, } \\
\text { wollastonita }\end{array}$ & 16,37 & 1,69 \\
\hline B7 & $\mathrm{XIX}$ & Holanda & $\begin{array}{l}\text { quartzo, calcita, anortita, hematita, gehlenita, } \\
\text { wollastonita }\end{array}$ & 17,77 & 1,58 \\
\hline S1-A & $\mathrm{XVI}$ & Espanha & $\begin{array}{l}\text { quartzo, calcita, anortita, hematita, gehlenita, } \\
\text { diopsídio }\end{array}$ & 28,90 & 1,39 \\
\hline S1-B & XVII & Portugal & quartzo, calcita, hematita, gehlenita, cristobalita & 42,39 & 1,12 \\
\hline S1-C & $\mathrm{XIX}$ & Portugal & $\begin{array}{l}\text { quartzo, calcita, anortita, hematita, gehlenita, } \\
\text { diopsídio }\end{array}$ & 18,21 & 1,68 \\
\hline S1-D & $\mathrm{XIX}$ & Alemanha & quartzo, calcita, anortita, hematita, mulita & 27,84 & 1,84 \\
\hline $\mathrm{S} 2$ & XVII & Portugal & $\begin{array}{l}\text { quartzo, calcita, hematita, gehlenita, wollastonita, } \\
\text { diopsídio }\end{array}$ & 19,90 & 1,61 \\
\hline S3 & $\mathrm{XVII}$ & Portugal & quartzo, calcita, hematita, gehlenita & 19,13 & 1,55 \\
\hline S4 & $\mathrm{XVII}$ & Portugal & $\begin{array}{l}\text { quartzo, calcita, anortita, hematita, gehlenita, } \\
\text { wollastonita, diopsídio }\end{array}$ & 21,58 & 1,56 \\
\hline S5 & $\mathrm{XIX}$ & Portugal & $\begin{array}{l}\text { quartzo, calcita, anortita, hematita, gehlenita, } \\
\text { diopsídio }\end{array}$ & 18,45 & 1,64 \\
\hline S6-A & $\mathrm{XIX}$ & Alemanha & quartzo, calcita, anortita, hematita, mulita (traços) & 13,93 & 1,84 \\
\hline S6-B & XVII & Portugal & quartzo, calcita, hematita, gehlenita, diopsídio & 18,76 & 1,62 \\
\hline S6-C & $\mathrm{XIX}$ & Inglaterra (provável) & quartzo, mulita, cristobalita, calcita & 13,50 & 1,90 \\
\hline
\end{tabular}

O material carbonático presente na matéria-prima das pastas pode reagir também com a sílica, originando novos minerais, como a wollastonita e o diopsí-

Tabela 1 - Composição mineralógica, porosidade e densidade da base cerâmica de azulejos antigos. 
dio, onde a primeira pode ser oriunda de uma reação com carbonato de cálcio (calcita) e o segundo com carbonato de cálcio e magnésio (dolomita).

A fase cristalina portadora de $\mathrm{Fe}$, encontrada nas amostras, é a hematita $\left(\mathrm{Fe}_{2} \mathrm{O}_{3}\right)$, com ponto de fusão a $1565^{\circ} \mathrm{C}$. Em determinados casos, sua ausência é indicada pela coloração branca do biscoito.

\section{Conclusões}

De acordo com a composição mineralógica, foi possível distribuir as amostras em três grupos, evidenciando a provável temperatura de queima e matéria-prima, como pode ser observado na Tabela 2 e que estão descritos a seguir.

\section{Grupo 1}

É composto por azulejos produzidos com técnicas advindas com a revolução industrial, na área da cerâmica, que correspondem às amostras $\mathrm{B} 2-\mathrm{A}, \mathrm{B} 2-\mathrm{B}$, B3 (quartzo, mullita e cristobalita); B4, S6-C (quartzo, mullita, cristobalita e calcita); B1-A, ver Figura 1, (quartzo, mullita, cristobalita, calcita e anortita). Tais amostras apresentam biscoito com coloração branca, provavelmente pela ausência de minerais com Fe na composição da matéria-prima, com exceção das amostras B2-A e B2-B, que são verdes em função da adição de pigmento na pasta.

A composição mineralógica desse grupo indica que a matéria-prima com que os azulejos foram fabricados atingiu temperaturas bastante elevadas. Tratase de uma argila refratária, na qual a ação do calor formou silicatos estáveis num intervalo de temperatura elevado, como é o caso da mullita e da cristobalita.

A presença de calcita nesse grupo, cujo ponto de fusão é $900^{\circ} \mathrm{C}$, inferior à temperatura de formação da mullita e da cristobalita (a partir de $1200^{\circ} \mathrm{C}$ ), pode ser um indicativo de que esse mineral não seja proveniente da matéria-prima usada no biscoito, mas, sim, do processo de carbonatação do hidróxido de cálcio existente nas argamassas de cal utilizadas no assentamento dos azulejos, que migrou para o corpo cerâmico através dos poros do material. Nesse caso, a questão da porosidade influencia diretamente na quantidade de hidróxido de cálcio que irá migrar para a base cerâmica do azulejo para constituir a calcita. Isto pode explicar a inexistência da calcita nas amostras B2-A, B2-B e B3, as quais possuem o menor índice de absorção total em água, $9,88 \%, 10,46 \%$ e $9,32 \%$, respectivamente, quando comparadas com as demais amostras (Tabela 1).

Antunes et al. (1995) encontraram esse mineral em azulejos portugueses do Palácio de São Bento em Lisboa, datados de 1670, e explicaram que a presença da calcita provavelmente ocorre devido a temperatura alcançada e o tempo de cozedura da sua fabricação não terem sido suficientes para conseguir um equilíbrio termodinâmico no biscoito, pois

Tabela 2 - Agrupamento das amostras de acordo com a sua mineralogia.

\begin{tabular}{|c|c|c|c|}
\hline Grupos & Amostras & Características da matéria-prima (argila) & $\begin{array}{l}\text { Temperatura } \\
\text { de queima }\end{array}$ \\
\hline \multirow{3}{*}{1} & B2-A, B2-B, B3 & \multirow{3}{*}{$\begin{array}{l}\text { Mineralogia básica: argilomineral (provavelmente caulinita) e } \\
\text { quartzo. Na amostra B1-A houve adição de carbonato (fundente), } \\
\text { conforme indica a anortita, que resulta da reação entre a caulinita e } \\
\text { a calcita. A calcita (B4, S6-C e B1-A) pode resultar da migração } \\
\text { pelos poros do material do hidróxido de cálcio da argamassa de } \\
\text { assentamento, ou da carbonatação do CaO não combinado durante } \\
\text { a cozedura. }\end{array}$} & \multirow{3}{*}{$1200-1728^{\circ} \mathrm{C}$} \\
\hline & B4, S6-C & & \\
\hline & B1-A & & \\
\hline \multirow{6}{*}{2} & $\mathrm{~B} 5, \mathrm{~B} 6, \mathrm{~B} 7$ & \multirow{6}{*}{$\begin{array}{l}\text { Mineralogia variada, formada principalmente por argilominerais } \\
\text { (provavelmente a caulinita), quartzo, calcita e/ou dolomita, e } \\
\text { hematita ou goethita. }\end{array}$} & \multirow{6}{*}{$900-1200^{\circ} \mathrm{C}$} \\
\hline & S1-A, S1-C, S5 & & \\
\hline & S6-B & & \\
\hline & $\mathrm{S} 2$ & & \\
\hline & S3 & & \\
\hline & S4 & & \\
\hline 3 & S1-B & $\begin{array}{l}\text { Mineralogia variada, com argilomineral (provavelmente a caulinita), } \\
\text { quartzo, calcita e/ou dolomita e hematita ou goethita. }\end{array}$ & $1200-1565^{\circ} \mathrm{C}$ \\
\hline
\end{tabular}


Thais A. B. Caminha Sanjad et al.

uma grande proporção de $\mathrm{CaO}$ ficou sem combinação e com o tempo sofreu carbonatação.

Com base na mineralogia dos azulejos do grupo um, concluiu-se que a temperatura de queima desses azulejos foi acima de $1200^{\circ} \mathrm{C}$, visto que, a partir dessa, ocorre a formação da mullita; e não ultrapassou $1728^{\circ} \mathrm{C}$, temperatura que corresponde ao ponto de fusão da cristobalita, o mais alto de todos os minerais encontrados nesse grupo.

\section{Grupo 2}

$\mathrm{O}$ segundo grupo é formado pelas seguintes amostras: B5, B6, B7 (quartzo, calcita, anortita, hematita, gehlenita e wollastonita); S1-A, S1-C, S5, S6-B (quartzo, calcita, anortita, hematita, gehlenita e diopsídio); S4, S2 (quartzo, calcita, anortita, hematita, gehlenita, wollastonita e diopsídio); S3 (quartzo, calcita, hematita e gehlenita).
Essa variedade mineralógica pode ser um indicativo de que a matéria-prima utilizada era constituída principalmente de quartzo, calcita e/ou dolomita, hematita ou goethita e argilominerais, principalmente caulinita (ver Figura 2). Por influência da composição mineralógica dessas amostras, que apresentam minerais com $\mathrm{Fe}$, os biscoitos desses azulejos mostram tonalidades que variam entre amarelada a rosada.

A temperatura de queima das amostras do grupo 2 provavelmente não ultrapassou $1200^{\circ} \mathrm{C}$, temperatura esta necessária para a formação da mullita e cristobalita, ausentes em todas as amostras. Possivelmente, a maior quantidade de carbonato, quando comparada com as amostras do grupo 1 , pode ter propiciado uma diminuição na temperatura de queima, que também pode ter sido causada pelos óxidos e/ ou hidróxidos de ferro, que também são fundentes.

\section{Grupo 3}

As amostras desse grupo são: S1B (quartzo, calcita, hematita, gehlenita, cristobalita); B1-B (quartzo, calcita, traços de hematita, gehlenita, diopsídio e traços de cristobalita) (Figura 3); S1-D e S6-A (quartzo, calcita, anortita, hematita e mullita). São azulejos produzidos com técnicas diferentes dos azulejos dos grupos anteriores, com exceção da amostra S1-B, proveniente do século XVII.

Os biscoitos desses azulejos apresentam tonalidade amarelo-clara (S1-B e B1-B) e vermelho-escura (S1-D e S6-A). Além disso, as amostras S1-B e B1-B apresentam biscoito com pequenas fissuras paralelas ao vidrado, indicando uma possível retração excessiva da pasta durante a cozedura.

Provavelmente a matéria-prima dessas amostras era semelhante à do grupo 2, formada principalmente por quartzo, calcita e/ou dolomita, hematita e/ou goethita e argilominerais. No entanto,

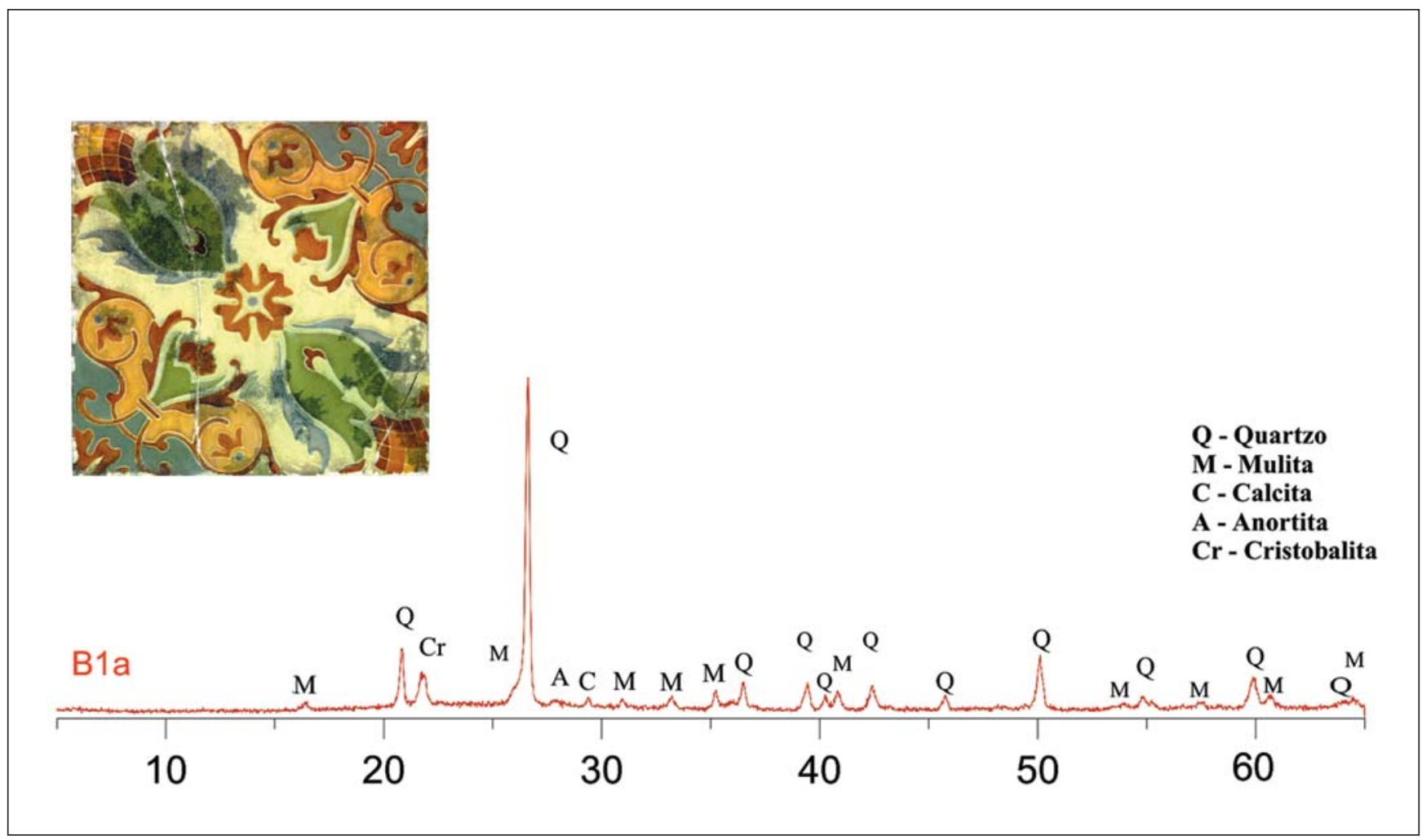

Figura 1 - Difratograma da amostra B1-A, com a imagem do azulejo analisado. Essa amostra de azulejo é do século XIX, da Fábrica Villeroy e Boch, Alemanha. 


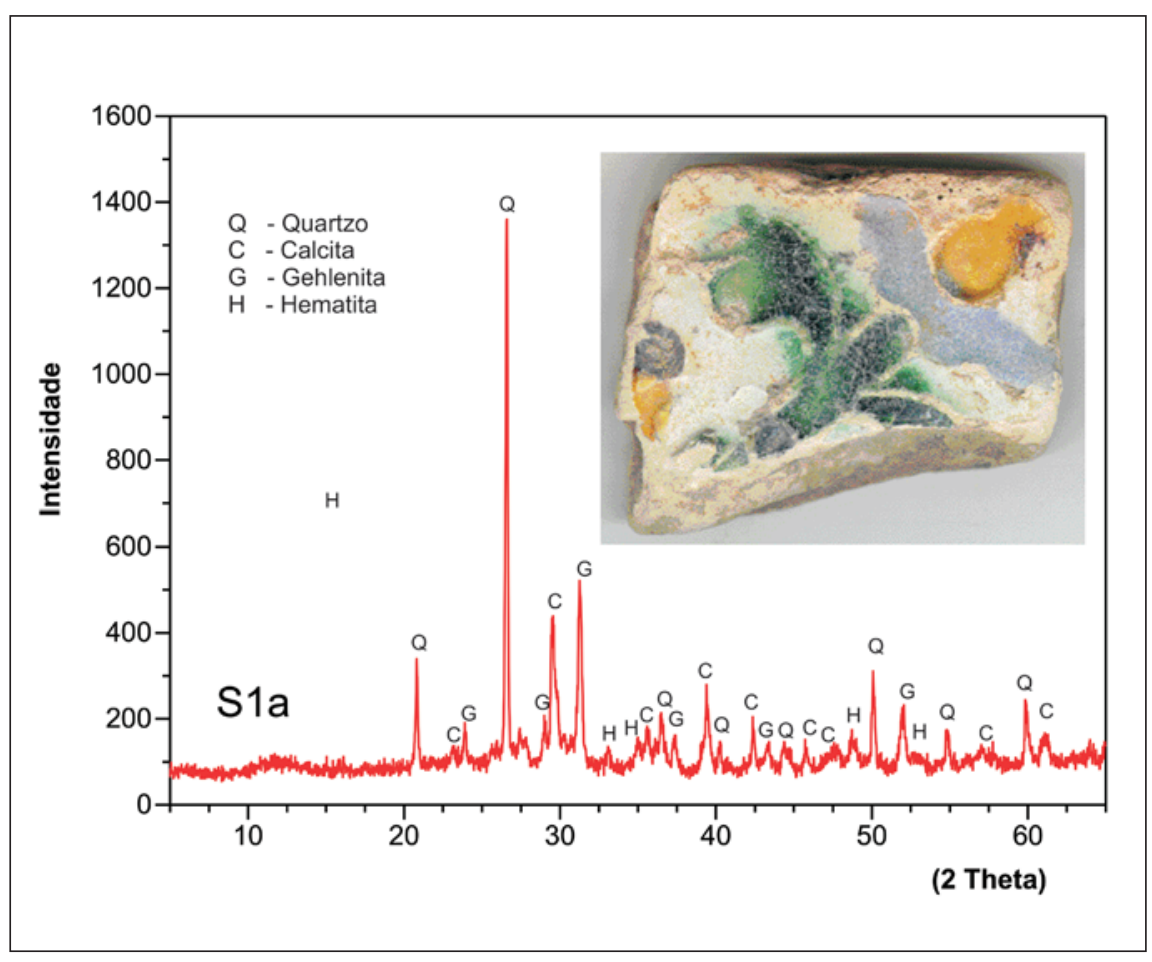

Figura 2 - Difratograma de raios $X$ da amostra S1-A, com a imagem do azulejo analisado, que é um fragmento de azulejo hispano-mourisco.

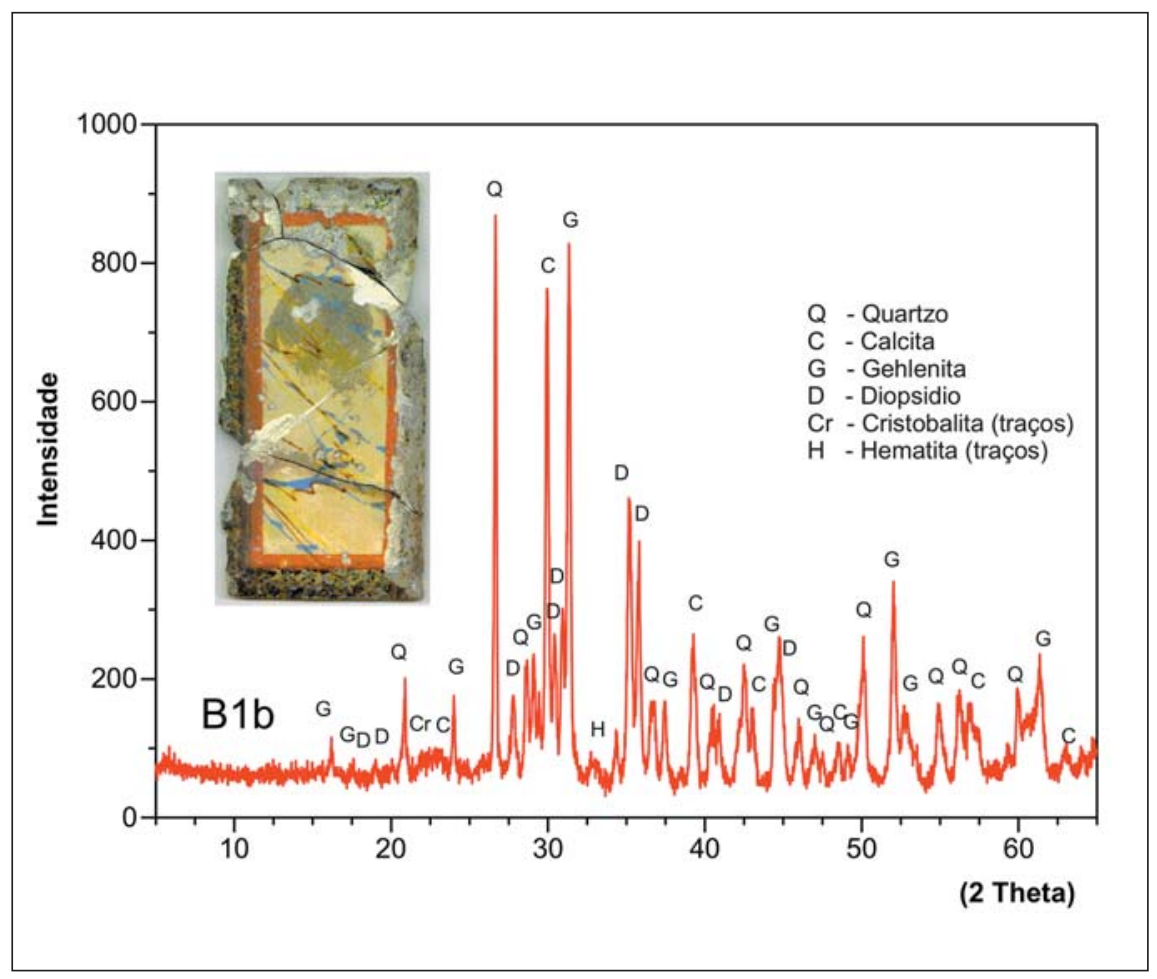

Figura 3 - Difratograma de raios X da amostra B1-B, com a imagem do azulejo analisado, do século XIX e de origem portuguesa. possivelmente a temperatura de queima foi superior a $1200^{\circ} \mathrm{C}$, para justificar a formação de mullita e de cristobalita, e inferior a $1565^{\circ} \mathrm{C}$, que é o ponto de fusão da hematita.

\section{Agradecimentos}

Ao CNPq pela bolsa de mestrado concedida. Aos professores do Instituto de Geociências da Universidade Federal da Bahia, Dr. Ilson Guimarães Carvalho (in memoriam) e Dr. Lucedino Paixão Ribeiro e ao químico do Núcleo de Tecnologia da Preservação e da Restauração da Escola Politécnica da Universidade Federal da Bahia, Allard Monteiro do Amaral. Aos dois anônimos revisores pelas importantes sugestões.

\section{Referências bibliográficas}

ANTUNES, J.L.F., FIGUEIREDO, M.O., PESSOA, J.C., FORTES, M.A. Characterization of Portuguese 17th Century tiles. In: INTERNATIONAL SYMPOSIUM "THE CERAMIC HERITAGE", WORLD CERAMICS CONGRESS, Proceedings... Florence: 1994. p. 653-660. 1995.

FABBRI, B., GUIDOTTI, C. R. Il restauro della ceramica. Firenze: Nardini Editore, 1993. 213p.

KIRSCH, H. Mineralogia aplicada. São Paulo: Ed. da Universidade de São Paulo, 1972. $291 \mathrm{p}$.

MALHOA, M. A importância do diagnóstico: intervenção de conservação e restauro da Igreja da Ordem Terceira de São Francisco da Penitência, Salvador, Bahia. In: Patrimônio azulejar brasileiro: aspectos históricos e de conservação. DIAS, M. C. V. L. (Org.). Brasília: Ministério da Cultura, 2001. p. 111-139.

OLIVEIRA, M. M. de. Materais de revestimento aplicados na conversação de azulejos. In: Patrimônio azulejar brasileiro: aspectos históricos e de conservação/ Org. Maria Cristina V. L. Dias. Brasília: Ministério da Cultura, p. 141-163, 2001.

SANTOS, P. de S. Ciência e tecnologia de argilas. São Paulo: Ed. Edgard Blücher, 1989. v.3.

SINGER, F., SINGER, S. Cerámica industrial. Bilbao: Ediciones Urmo, 1971. v. 1, 762p.

VLACK, L. H. van. Propriedades dos materiais cerâmicos. São Paulo: Ed. da Universidade de São Paulo, 1973. 318p.

Artigo recebido em 18/09/2002 e aprovado em 04/11/2004. 